\title{
AMMI and GGE Biplot Analysis of Yield Stability and Adaptability of Elite Genotypes of Bread Wheat (Triticum aestivum L.) for Northern Hill Zone of India
}

\author{
M. S. Jeberson ${ }^{1 *}$, L. Kant ${ }^{2}$, N. Kishore ${ }^{3}$, V. Rana ${ }^{3}$, D. P. Walia ${ }^{4}$ and D. Singh ${ }^{3}$ \\ ${ }^{1}$ AICRP (MULLaRP), Directorate of Research, Central Agricultural University, Imphal, Manipur (795 001), India \\ ${ }^{2}$ Division of Crop Improvement, VPKAS, Almora, Uttarakhand (263 101), India \\ ${ }^{3}$ CSKHPKV, HAREC, Bajaura, Kullu, Himachal Pradesh (174 029), India \\ ${ }^{4}$ IARI, Regional Research Station, Tutukandi, Shimla, Himachal Pradesh (171 004), India
}

\section{Corresponding Author}

M. S. Jeberson

e-mail: samuel8142@gmail.com

\author{
Article History \\ Article ID: AR1838 \\ Received in $24^{\text {th }}$ August, 2017 \\ Received in revised form $20^{\text {th }}$ September, 2017 \\ Accepted in final form $7^{\text {th }}$ October, 2017
}

\begin{abstract}
Bread wheat (Triticum aestivum L.) is a major food grain in India next to rice. Therefore, improving yield and yield stability is the primary objective of wheat breeding programmes in this country. The eleven wheat genotypes were evaluated under eight locations representing typical rainfed conditions of the North Hill Zone. The study based on AMMI and GGE biplot analysis methods to highlight the G×E interaction in multi-location trials and stratification of genotypes as per their adaptability for rainfed conditions of the northern hill zone. Combined ANOVA analysis showed highly significant differences $(p<0.001)$ of 11 genotypes under rainfed conditions of North Hill Zone. Highly significant environments, genotypes and GXE interaction explained $81.4 \%, 2.3 \%$ and $15.7 \%$ of the total sum of squares, respectively (Table 2 ). The significant GE interaction sum of squares is further portioned into seven significant Interaction Principal Components Axes (IPCAs) and a residual term. The first four interaction principal component analysis (IPCA1, IPCA2, IPCA3 and IPCA4) explained 33.6\%, 28.1\%, 19.5\% and $10.0 \%$ of the G×E interaction variation, respectively. Accordingly AMMI analysis for stability, genotypes G15, G3, G8, and G1 were shown to have a higher stability for yield than other genotypes. The GGE biplot analysis shown that the genotypes G10, G5, G7 and G1 were corner genotypes and suited to particular environments.
\end{abstract}

Keywords: Bread wheat, environment, GGE, AMMI, stability

\section{Introduction}

Bread wheat (Triticum aestivum L.) is a major food grain in India next to rice. Therefore, improving yield and yield stability is the primary objective of wheat breeding programmes in this country. The grain of wheat represents elementary source of nutrition for large part of human population. In Manipur, wheat cultivation is being practiced under restricted irrigated condition in recent years. Genotype-location (GL) interaction effects are of special interest for breeding programmes to identify adaptation targets, adaptive traits and test sites. These interaction effects, generally having relatively low repeatability between years, should be studied on a multiyear basis in annual crops. With the biplot facility from AMMI analysis, both genotypes and locations occur on the same scattergram, and inferences about specific genotype $x$ location combinations can be made (Annicchiarico, 1997).. The biplot methodology was demonstrated by MET data of barley (Hordeum vulgare L.) conducted across North America (Yan and Tinker, 2005). AMMI (additive main effects and multiplicative interaction) analysis and GGE biplot analysis were widely used a multivariate technique for interaction investigation (Mohammadi et al., 2010). The AMMI model was more effective in partitioning the interaction SS than the linear regression technique (Nachit et al., 1992; Gauch, 1992). However, the performance of a genotype in a given environment is more important for wheat cultivation and improvement (Li et al., 2006). These methods have been found effective as it captures a large portion of the interaction sum of squares; at the same time separates main as well as interaction effects and shows that which genotype will be suitable for which environment. The meaningful interpretation of data to support a breeding program such as genotype stability is necessary at multi location trials. The AMMI and GGE biplot models have been used extensively in recent past to analyze and interpret genotypexenvironment interactions and results can be displayed graphically. Another powerful statistical model that addresses some of the disadvantages of AMMI is the GGE biplot. The method is effective for identifying the best-performing cultivar across environments, identifying 
the best cultivars for mega-environment differentiation, and evaluating the yield and stability of genotypes (Yan et al., 2000; Yan and Kang, 2003). According to the GGE biplot, a highly stable genotype would have a shorter projection on to the average environment coordinate (AEC) abscissa, irrespective of its direction (Yan and Kang, 2003). These two statistical analyses (AMMI and GGE) have broader relevance for agricultural researchers because they pertain to any twoway data matrices, and such data emerge from many kinds of experiments (Gauch, 2006). Genotype by environment interaction (GEI) is commonly observed by breeders as a differential ranking of genotype yields among locations and years (Ahmadi et al., 2012).

The eleven wheat genotypes were evaluated under eight locations representing typical rainfed conditions of the North Hill Zone. The study based on AMMI and GGE biplot analysis methods to highlight the G×E interaction in multilocation trials and stratification of genotypes as per their adaptability for rainfed conditions of the northern hill zone. The major objectives of the investigation were (i) to identify wheat genotypes with high and stable yield across restricted irrigation condition of $\mathrm{NHZ}$ (ii) to study the relationships, similarities, and dissimilarities among yield-stability statistics carried out to quantify GE interaction effects on yield.

\section{Materials and Methods}

\subsection{Plant materials}

Field experiments under restricted irrigation condition were conducted at eight different research stations in India, which included Almora, Majhera, Dhaulakuan, Malan, Shimla, Bajaura, Kalimpong and Imphal. The genotypes were evaluated in 2014-15 for yield. The names and origin of the genotypes are provided in Table 1 . The experiments were carried out in a randomized complete block design (RCBD) with six replications over all environments. The experimental plots consisted of 6 rows of $4 \mathrm{~m}$ length each. Row-to-row and plant-to-plant distances were kept at $20 \mathrm{~cm}$ and $5 \mathrm{~cm}$, respectively at all the environments. Data on seed yield were taken from the middle 4 rows of each plot, leaving aside the guard rows on either side of a plot. The PROC GLM procedure available in SAS (Ver. 9.3, SAS Institute, 2004) was used to partition yield variation into environment, genotype, and genotypexenvironment interaction. The grain yield data were subjected to AMMI and GGE biplots analysis. The results of the AMMI model analysis were interpreted from the AMMI1 graph that showed the main and first multiplicative axis term (PC1) of both genotypes and environments. The GGE biplots were constructed from the first two principal components (PC1 and PC2) derived by subjecting the environmentcentered yield data (which contains $G$ and GE) to singular valued composition (SVD) (Yan, 2000; Yan and Rajcan, 2002). The PBtools software (PBtools for windows, 2013) was used to generate graphs showing (i) "which-won-where" pattern, (ii) ranking of cultivars on the basis of yield and stability, and (iii) correlation vectors among environments. Angles between environment vectors were used to judge correlations (similarities/dissimilarities) between pairs of environments (Yan and Kang, 2003).

\section{Results and Discussion}

Combined ANOVA analysis showed highly significant differences $(p<0.001)$ of 11 genotypes under rainfed conditions of North Hill Zone (Table 2). Similar results were obtained by Homma (2015); Kadhem and Baktash (2016). The significant interaction suggests that yield of genotypes

\begin{tabular}{|c|c|c|c|c|c|c|c|}
\hline Code & Location & State & $\begin{array}{l}\text { Altitude } \\
(\mathrm{m})\end{array}$ & Latitude/ Longitude & Soil texture & $\begin{array}{l}\text { Annual rainfall } \\
(\mathrm{mm})\end{array}$ & $\begin{array}{c}\text { Yield } \\
\left(\mathrm{kg} \mathrm{ha}^{-1}\right)\end{array}$ \\
\hline 1. & Almora & Uttarakhand & 1642 & $\begin{array}{l}29^{\circ} 35^{\prime} 39.0804^{\prime \prime} \mathrm{N} \text { and } \\
79^{\circ} 39^{\prime} 14.0148^{\prime \prime} \mathrm{E} .\end{array}$ & Red loam & 775.7 & 40.0 \\
\hline 2. & Majhera & -do- & 1532 & $\begin{array}{l}29^{\circ} 16^{\prime} 6 \mathrm{~N} \\
80^{\circ} 5^{\prime} 19 \mathrm{E}\end{array}$ & Red loam & 638.6 & 30.8 \\
\hline 3. & Dhaulakuan & $\begin{array}{l}\text { Himachal } \\
\text { Pradesh }\end{array}$ & 468 & $30004^{\prime} \mathrm{N}$ and 750 05' E & Sandy loam & 1206 & 27.1 \\
\hline 4. & Malan & -do- & 408 & $32^{\circ} 02^{\prime} \mathrm{N}$ and $76^{\circ} 03^{\prime} \mathrm{E}$ & Clay loam & 3400 & 37.1 \\
\hline 5. & Shimla & - do- & 2195 & $\begin{array}{c}31^{\circ} 6^{\prime} 16.5780^{\prime \prime} \mathrm{N} \text { and } \\
77^{\circ} 10^{\prime} 24.3264^{\prime \prime} \mathrm{E}\end{array}$ & $\begin{array}{l}\text { Silt loam, } \\
\text { clay loam }\end{array}$ & 1575 & 18.5 \\
\hline 6. & Bajaura & -do- & 1085 & $\begin{array}{c}31^{\circ} 50^{\prime} 54.2472^{\prime \prime} \mathrm{N} \text { and } \\
77^{\circ} 9^{\prime} 51.6132^{\prime \prime} \mathrm{E}\end{array}$ & $\begin{array}{l}\text { Sandy loam, } \\
\text { clay loam }\end{array}$ & 1500 & 25.5 \\
\hline 7. & Kalimpong & Sikkim & 1121 & $\begin{array}{l}27^{\circ} 4^{\prime} 0.0048^{\prime \prime} \mathrm{N} \text { and } \\
88^{\circ} 28^{\prime} 0.0012^{\prime \prime} \mathrm{E} \text {. }\end{array}$ & Red loam & 3327 & 24.8 \\
\hline 8. & Imphal & Manipur & 784 & $\begin{array}{c}24^{\circ} 48^{\prime} 50.2812^{\prime \prime} \mathrm{N} \text { and } \\
93^{\circ} 57^{\prime} 1.0044^{\prime \prime} \mathrm{E}\end{array}$ & Clay loam & 1581 & 17.0 \\
\hline
\end{tabular}




\begin{tabular}{|c|c|c|c|}
\hline $\begin{array}{l}\text { SI. } \\
\text { No. }\end{array}$ & $\begin{array}{l}\text { Geno- } \\
\text { type }\end{array}$ & Pedigree & Place \\
\hline 1. & VL 3009 & $\begin{array}{l}\text { MELON//FILIN/ } \\
\text { MILAN/3/FILIN }\end{array}$ & $\begin{array}{l}\text { VPKAS(ICAR), Almora, } \\
\text { UK }\end{array}$ \\
\hline 2. & HPW 421 & HD29/HS 240-P1 & CSKHPKV, Malan, UK \\
\hline 3. & HS 600 & HS 469/DL 460 & $\begin{array}{l}\text { IARI, Regional Station, } \\
\text { Shimla, HP }\end{array}$ \\
\hline 4. & HPW 422 & HPW 155/HD 29 & CSKHPKV, Malan, UK \\
\hline 5. & HS 599 & VL 864/FLW 3 & $\begin{array}{l}\text { IARI, Regional Station, } \\
\text { Shimla, HP }\end{array}$ \\
\hline 6. & UP 2918 & $\begin{array}{l}\text { HPW89/UP2520/ } \\
\text { UP2382/DBW } 17\end{array}$ & $\begin{array}{l}\text { GBPUAT, Pantnagar, } \\
\text { UK }\end{array}$ \\
\hline 7. & VL 3008 & $\begin{array}{l}\text { HW } 3067 / P C K / \\
\text { VEE//VL900 }\end{array}$ & $\begin{array}{l}\text { VPKAS(ICAR), Almora, } \\
\text { UK }\end{array}$ \\
\hline 8. & HS 601 & $\begin{array}{l}\text { SERI. I B * 2 / / } \\
\text { KAUZ*3/BOW/3/ } \\
\text { FR T L / C M H } \\
83.2517\end{array}$ & $\begin{array}{l}\text { IARI, Regional Station, } \\
\text { Shimla, HP }\end{array}$ \\
\hline 9. & VL 3007 & VL868/VL852 & $\begin{array}{l}\text { VPKAS(ICAR), Almora, } \\
\text { UK }\end{array}$ \\
\hline 10. & HS 490 & $\begin{array}{l}\text { HS364/HPW114// } \\
\text { HS240//HS } 346\end{array}$ & $\begin{array}{l}\text { IARI, Regional Station, } \\
\text { Shimla, HP }\end{array}$ \\
\hline 11 & VL 892 & WH 542/PBW 226 & $\begin{array}{l}\text { VPKAS(ICAR), Almora, } \\
\text { UK }\end{array}$ \\
\hline
\end{tabular}

varied across rainfed conditions of the northern hill zone. The mean grain yield of genotypes investigated varied from $25.7 \mathrm{q} \mathrm{ha}^{-1}$ (UP 2198 and VL 3008) to 29.7 (VL 892) q haunder all locations of the zone. VL 892 recorded highest grain yield (29.7 q ha-1) over all environments followed by HPW
422 and HS 490 (Table 3). Almora showed maximum average yield of wheat genotypes followed by Malan and Majhera. Not a single genotype exhibited superiority over more than one location. This justified the interaction among genotype and environment. The magnitude of the GXE sum of squares 29.35 was about 5 times larger than that for genotypes sum of squares 5.49 , indicating sizeable differences in genotypic response across environments. This advocates the possible presence of different genotype groups (Mohammadi et al., 2011). The mean squares of the PCA1 and PCA2 were significant at $p=0.05$ and collectively contributed to $61.73 \%$ of the total GxE. Both the PCA1 and PCA2 scores revealed that genotype VL 892 was the most stable genotype across the environments.

\subsection{AMMI analysis}

Highly significant environments, genotypes and GXE interaction explained $81.4 \%, 2.3 \%$ and $15.7 \%$ of the total sum of squares, respectively (Table 2). The significant GE interaction sum of squares is further portioned into seven significant Interaction Principal Components Axes (IPCAs) and a residual term. The first four interaction principal component analysis (IPCA1, IPCA2, IPCA3 and IPCA4) explained $33.6 \%, 28.1 \%, 19.5 \%$ and $10.0 \%$ of the GXE interaction variation, respectively. Similar results were obtained by Verma et al. (2015) in wheat.

These four IPCAs revealed $91.2 \%$ of variation of the total sum of squares due to the interaction. The remaining $8.8 \%$ of the interaction effect being the residual or noise, therefore, not interpreted and hence removed (Gauch, 1992; Purchase et al., 2000). The variation contributed by these four IPCAs showed differential performance of genotypes for grain yield across the locations. However, for the confirmation of the variation revealed by GxE, the first two multiplicative component axes were sufficient (Gauch, 2006), which explained $61.7 \%$ of the total GxE variation among the wheat

\begin{tabular}{lccccccccc}
\hline \multicolumn{1}{l}{ Table 3: Mean yield ha $^{-1}$ of wheat genotypes raised in different locations } \\
\hline Genotype & Almora & Majhera & Dhaulakuan & Malan & Shimla & Bajaura & Kalimpong & Imphal & Mean \\
\hline VL 3009 & 41.1 & 30.8 & 24.7 & 35.2 & 17.4 & 30.6 & 19.3 & 26 & 28.1 \\
HPW421 & 34.3 & 29.1 & 23.9 & 35.9 & 18.2 & 22.6 & 28.2 & 19.6 & 26.5 \\
HS 600 & 44.3 & 35.4 & 27.9 & 31.1 & 18 & 27.1 & 29.1 & 13.3 & 28.3 \\
HPW422 & 39.9 & 29.1 & 29.1 & 41.3 & 24 & 24.8 & 26.1 & 21.9 & 29.5 \\
HS 599 & 35 & 32.9 & 28.8 & 39.6 & 18.8 & 23.7 & 26.5 & 11.2 & 27.1 \\
UP 2918 & 39.1 & 29.9 & 26.5 & 38 & 16.8 & 14.6 & 27.5 & 12.8 & 25.7 \\
VL 3008 & 40.6 & 28.1 & 24.9 & 32.2 & 14 & 23 & 23.5 & 19.5 & 25.7 \\
HS 601 & 46.7 & 33.7 & 32.8 & 34.3 & 22.4 & 28 & 20.1 & 10.4 & 28.6 \\
VL 3007 & 35.8 & 27.8 & 25.5 & 41.2 & 17.3 & 26.9 & 17.9 & 14 & 25.8 \\
HS 490 & 41.4 & 34.7 & 22.4 & 38.4 & 16.2 & 30.3 & 26.1 & 19.7 & 28.7 \\
VL 892 & 41.6 & 27 & 31.5 & 41.1 & 20.8 & 28.8 & 28.3 & 18.3 & 29.7 \\
Location Mean & 40.0 & 30.8 & 27.1 & 37.1 & 18.5 & 25.5 & 24.8 & 17.0 & 27.6 \\
\hline
\end{tabular}


genotypes in this experiment. This is due to the prominent reduction of dimensionality and graphical visualization for the adaptation patterns of genotypes (Annicchiarico, 2002). The results were in corroboration with the previous research results which showed similar higher magnitude of GEI variance revealed by the first two principal components of GEI (Fufa, 2013; Solomon et al., 2008; Verma et al., 2015).

\subsection{AMMI biplot analysis}

There are two basic AMMI biplots, the AMMI 1 biplot, where the main effect (Genotype and Environment means) and IPCA-I scores are plotted against each other (Figure 1) and AMMI 2 biplot, where scores of IPCA-I and IPCA-2 are plotted against each other (Figure 2). In AMMI 1 biplot, the differences among genotypes in terms of direction and magnitude along the $X$-axis (yield) and $\mathrm{Y}$ axis (IPCA 1 scores) are important. In the

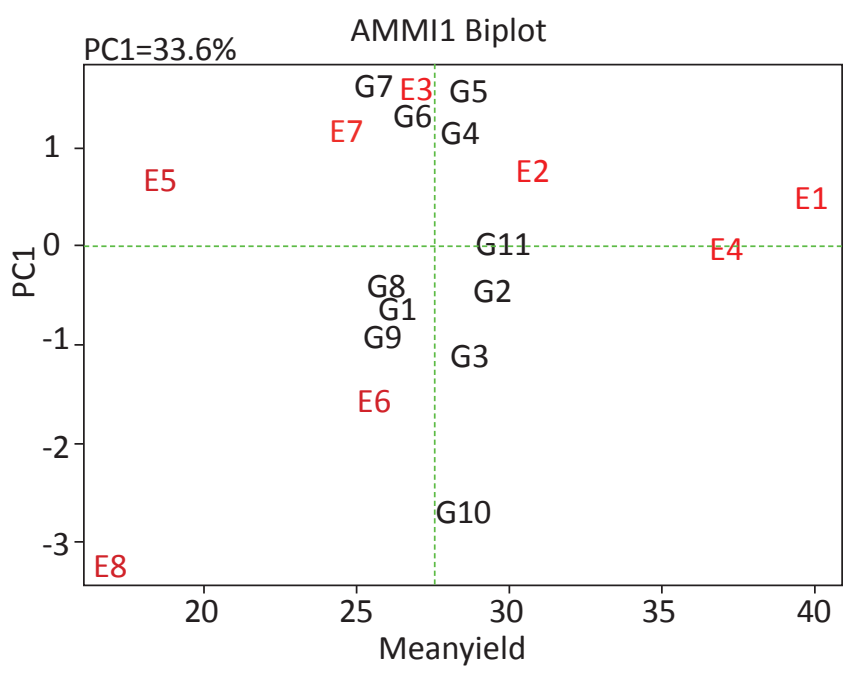

Figure 1: AMMI 1 biplot for additive effects vs. IPCA1 in 11 promising lines of wheat from eight environments

AMMI1 Biplot for meanyield

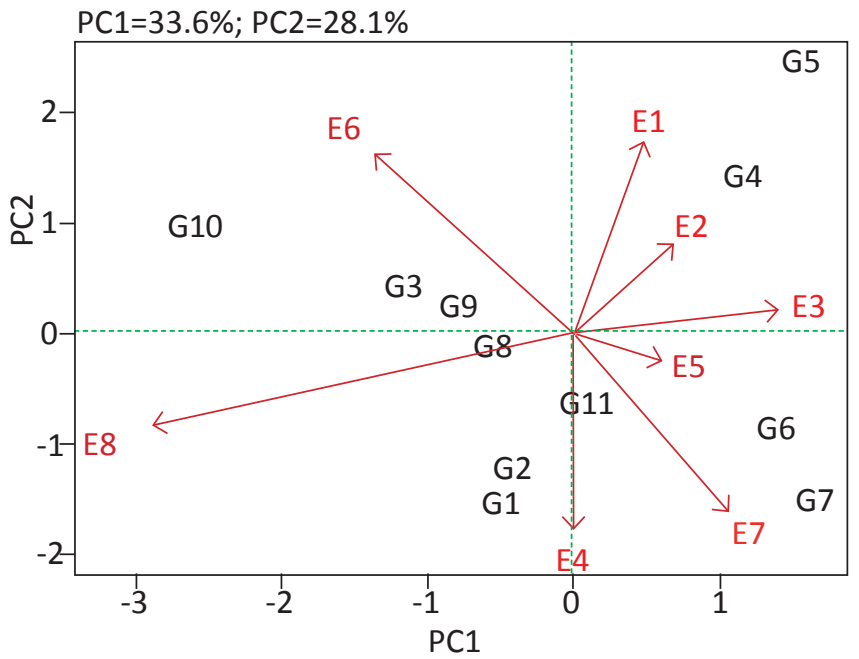

Figure 2: AMMI 2 biplot showing the two main axes of interaction (IPCA2 vs. IPCA1) in 11 promising lines from eight environments biplot display, genotypes or environments that appear almost on a perpendicular line of the graph had similar mean yields and those that fall almost on a horizontal line had similar interaction. Genotypes or environments on the right side of the midpoint of the perpendicular line have higher yields than those on the left side. The score and sign of IPCA1 reflect the magnitude of the contribution of both genotypes and environments to $\mathrm{GEl}$, where scores near zero are characteristic of stability, whereas higher score (absolute value) considered as unstable and specifically adapted to certain environment. The characterization of each promising line (genotype) to mean grain yield and contribution to GEI by mean of IPCA1 (Figure 1) indicates that genotypes $\mathrm{G} 4$ and $\mathrm{G} 5$ were specifically adapted to high yielding environments (E1 and E2) with grain yield more than grand average yield (Figure 1), and with respect to their contribution to GEI (i.e. stability) the IPCA1 score, G4 and G5 was the most stable genotype to higher yielding environments, $\mathrm{G} 2$ was more stable in comparison to G7, G9, and G10. However, G3, G1, and G13 were low yielding genotypes and relatively stable. On the other hand, genotypes G6, G14, and G11 were adapted to low yielding environment but not stable. G15, G3, G8, and G1 were near to zero IPCA1 by which it was shown to have a higher stability for yield than other genotypes (Figure 1). This finding was in agreement with Kadhem and Baktash (2016), Muhammad et al. (2013) and Verma et al. (2016). The best genotype needs to combine good grain yield and stable performance across a range of production environments. For example, genotype G15 can be judged based on its stability over the environments, which combined low absolute IPCA-I score with good grain yield and was the overall winner with less variable yield across the environments explaining its suitability as one of the leading promising line for such trials. The environments showed much variability in both additive main effects and interactions (Table 4). The potential environments (E3, E4, and E5) having high positive IPCAI score showed differential performance of genotypes for grain yield (Table 5). The lowest yielding

Table 4: AMMI analysis of variance for spring wheat grain yield $\left(\mathrm{t} \mathrm{ha}^{-1}\right)$ of the genotypes across the 8 environments

\begin{tabular}{lccccc}
\hline Source & D.F & SS & MS & $F$ & $\begin{array}{c}\text { \% TSS ex- } \\
\text { plained }\end{array}$ \\
\hline Environment & 7 & 152.36 & 21.77 & 137.74 & 81.39 \\
Genotype & 10 & 5.49 & 0.55 & 3.47 & 2.93 \\
Envxgenotype & 70 & 29.35 & 0.42 & 2.65 & 15.68 \\
AMMI 1 & 16 & 9.87 & 0.62 & 3.90 & 33.6 \\
AMMI2 & 14 & 8.25 & 0.59 & 3.73 & 28.1 \\
AMMI3 & 12 & 5.71 & 0.48 & 3.01 & 19.5 \\
AMMI4 & 10 & 2.94 & 0.29 & 1.86 & 10.0 \\
AMMI5 & 8 & 1.37 & 0.17 & 1.09 & 4.7 \\
AMMI6 & 6 & 0.91 & 0.15 & 0.96 & 3.1 \\
AMMI7 & 4 & 0.30 & 0.07 & 0.47 & 1.0 \\
Total & 87 & 187.21 & & & \\
\hline
\end{tabular}




\begin{tabular}{lcccccc}
\hline \multicolumn{7}{l}{ Table 5: The first two IPCA scores, ASV and ASV rank for the genotypes } \\
\hline Genotype & NAME & Yield $\left(\mathrm{kg} \mathrm{ha}^{-1}\right)$ & IPCA1 & IPCA2 & ASV & ASV Rank \\
\hline 1 & VL 3009 & 2.81 & 0.8288 & 0.3202 & 0.9614 & 10 \\
2 & HS 490 & 2.87 & 0.3477 & 0.1432 & 0.4064 & 5 \\
3 & VL 892 & 2.97 & -0.0213 & -0.1795 & 0.1810 & 2 \\
4 & HPW 421 & 2.65 & 0.1671 & -0.4790 & 0.5127 & 6 \\
5 & HS 600 & 2.83 & -0.3720 & 0.4572 & 0.6120 & 8 \\
6 & HPW 422 & 2.95 & 0.1330 & -0.3724 & 0.3998 & 4 \\
7 & HS 599 & 2.71 & -0.4418 & -0.2569 & 0.5473 & 7 \\
8 & UP 2918 & 2.57 & -0.5275 & -0.4808 & 0.7511 & 9 \\
9 & VL 3008 & 2.57 & 0.2482 & 0.0886 & 0.2855 & 3 \\
10 & HS 601 & 2.86 & -0.5135 & 0.7874 & 0.9672 & 11 \\
11 & VL 3007 & 2.58 & 0.1513 & -0.0279 & 0.1678 & 1 \\
Environment & & & & & 0.6524 & 6 \\
\hline 1 & Almora & 4.00 & -0.1691 & 0.6256 & 0.4057 & 2 \\
2 & Majhera & 3.08 & -0.2467 & 0.3030 & 0.5520 & 3 \\
3 & Dhaulakuan & 2.71 & -0.4993 & 0.0798 & 0.6325 & 5 \\
4 & Malan & 3.71 & 0.0011 & -0.6325 & 0.2621 & 1 \\
5 & Shimla & 1.85 & -0.2235 & -0.0947 & 0.5869 & 4 \\
6 & Bajaura & 2.55 & 0.4897 & 0.5869 & 0.7041 & 7 \\
7 & Kalimpong & 2.48 & -0.3745 & -0.5727 & 1.1565 & 8 \\
8 & Imphal & 1.70 & 1.0223 & -0.2953 & & \\
\hline
\end{tabular}

environment (E2) had recorded lowest but negative IPCAI score suggesting that all the genotypes poorly performed under this environment. This indicates the reason in most of the variation in grain yield, and that were clearly noticed in Figure 1 were E1, E2 and E4 were clustered together and characterized by more productive environments. Because, they are having highest positive IPCA1 score. These results are in line with the findings of Ahmadi et al. (2012) and Suneetha et al. (2013).

The biplot analysis is useful for identifying the high yielding genotypes visually for each environment. Genotypes being far away from the beginning of biplot graph are joined with straight line so that polygon is formed with all other genotypes being found within the polygon. In this investigation, genotypes found in the corners, G10, G5, G7 and G1 had the highest seed yield ha ${ }^{-1}$ in their sector. Similar result was obtained by Mehari et al. (2015).

According to the biplot shown in Figure 3, the corner genotypes that are the most responsive ones can be visually determined. These corner genotypes were G10, G5, G7 and G1. In this figure, locations are divided into four sectors. The first sector made up of E6 and E8, with genotype $\mathrm{G} 10$ as the most favorable. The second sector represents E1, E2, E3 and E5 with genotype G5 as the most favorable. The third sector represents E7 with genotype $\mathrm{G} 7$ as the most favorable. The fourth sector represents $E 4$, with genotype $G 1$ as the winning genotype. Also, those entries within the polygon (for example $\mathrm{G} 2$ and $\mathrm{G} 3$ for $\mathrm{E} 6$ and $\mathrm{E} 8$ ) were less responsive to location than the corner genotypes. If mega-environments are identified by different winning genotypes (Gauch and Zobel, 1996), Figure 3 indicates the existence of four mega-environments for wheat in northern hill zone, namely the G10-winning place (subtropical climatic condition), G5-winning place (cold climatic region), G7-winning place (cold climatic region) and G1 winning place (moderate climatic condition). However, this subdivision pattern can only be considered as a suggestion as it is based exclusively on one MET dataset.

Based on Figure 3, it is possible to assess both mean yield and stability performance through a biplot. An average tester coordinate (ATC) horizontal axis passes through the biplot origin and the average location and the oval show the positive end of the ATC horizontal axis. The average yields of genotypes are estimated by projections of their markers on the ATC horizontal axis. Thus, genotype G5 had the highest average yield, and G7 had the lowest (Figure 4). Stability of each genotype is explored by its projection onto the ATC vertical axis. The smaller the total length of projection of a genotype, the more stable it is. Thus, genotypes G11, G8, G9 and G2 were the most stable and genotypes G7, G1, 


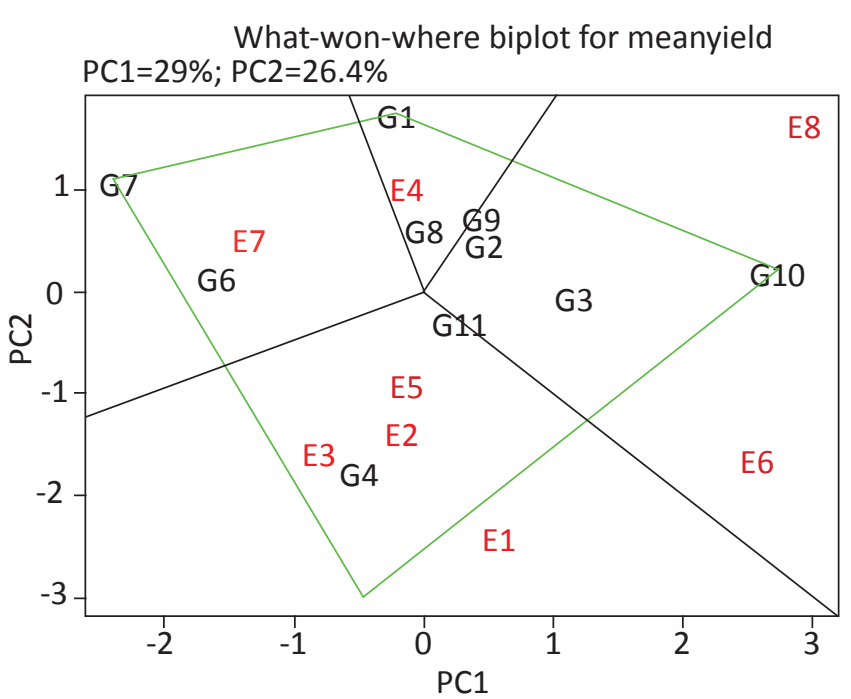

Figure 3: The polygon view of the genotype+genotype by environment plot for grain yield

GGE biplot-genotype view for meanyield

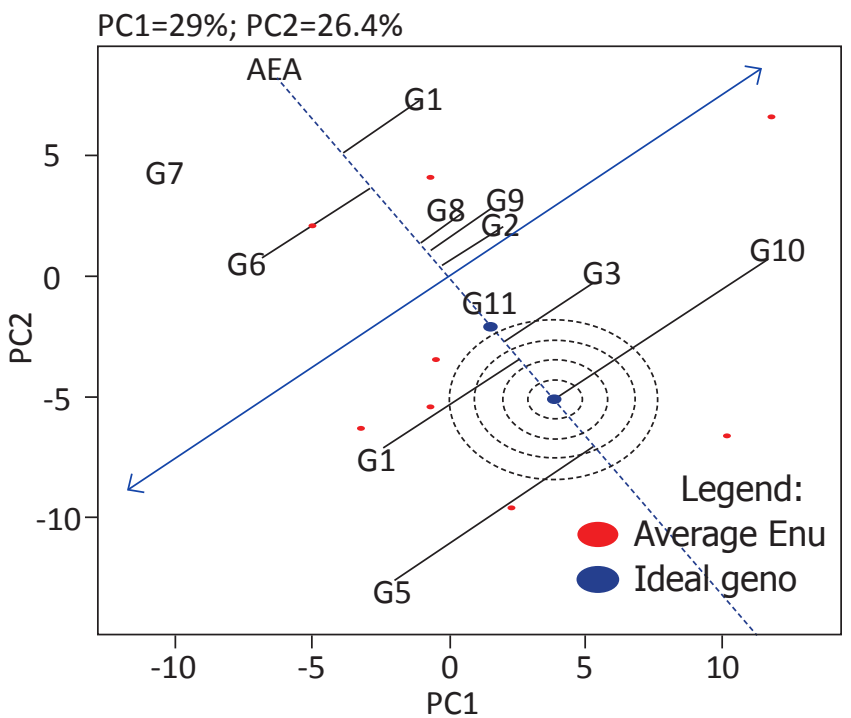

Figure 4: GGE biplot of mean and stability of 11 wheat genotypes for yield and specific genotypexenvironment interactions

G6, G3 and G4 were the stable. For two genotypes G5 and $\mathrm{G} 10$, projections were more and were considered as least stable which means they are suitable for particular locations only. However, considering both mean yield and stability performance, genotypes G11, G4, G8, G3 and G1 could be regarded as the most favorable. Yield performances consist of mean yield and stability concepts. Plant breeders always look at genotypes that indicate yield stability along with high yield across environments (Kang, 2002). Estimates for stability resulting from an analysis of GXE interaction (Hill et al., 1998) and the significant GE interaction have resulted from changes in the magnitude of differences between genotypes in different environments. If no GE interaction exists, the mean difference among the studied entries summoned by the observed phenotypes in different environments remains constant (Karimizadeh et al., 2013).

\section{Conclusion}

Accordingly, AMMI analysis for stability, genotypes G15, G3, G8, and G1 were shown to have a higher stability for yield than other genotypes. The GGE biplot analysis shown that the genotypes G10, G5, G7 and G1 were corner genotypes and suited to particular environments. These two methods can be effectively utilized for the identification of the suitable genotypes for suitable environments.

\section{Acknowledgement}

The authors are thanks the Indian Institute Wheat and Barley Research, Karnal, Haryana, for providing the fund and wheat germplasm to carry out the experiment. I am also grateful to the Directorate of Research, CAU, Imphal, Division of Crop Improvement, VPKAS, Almora, Uttarakhand, CSKHPKV, HAREC, Bajaura, Kullu, Himachal Pradesh and IARI, Regional Research Station, Tutukandi, Shimla, Himachal Pradesh for necessary facility to conduct the research.

\section{References}

Ahmadi, J., Mohammadi, A., Najafi Mirak, T., 2012. Targeting Promising Bread Wheat (Triticum aestivum L.) Lines for Cold Climate Growing Environments Using AMMI and SREG GGE Biplot Analyses. Journal of Agriculture Science and Technology 4, 645-657.

Annicchiarico, P., 2002. Defining adaptation strategies and yield stability targets in breeding programs. In: Kang, M.S. (Ed.), Quantitative Genetics, Genomics, and Plant Breeding, CABI, Wallingford, UK, 365-383.

Crossa, J., Fox, P.N., Pfeiffer, W.H., Rajaram, S., Gauch, Jr. H.G., 1991. AMMI adjustment for statistical analysis of an international wheat yield trial. Theoretical and Applied Genetics 81, 27-37.

Fufa, M., 2013. AMMI Analysis of Tuber Yield of Potato Genotypes Grown in Bale, Southeastern Ethiopia. Advances in Crop Science and Technology 2(1), 120-122.

Gauch, H.G., 1992. Statistical analysis of regional yield trials: AMMI analysis of factorial designs. Elsevier, Amsterdam, Netherlands.

Gauch, H.G., 2006. Statistical analysis of yield trials by AMMI and GGE. Crop Science 46, 1488-1500.

Gauch, H.G., Zobel, R.W., 1996. AMMI analysis of yield trials. In M.S. Kang \& H.G. Gauch, eds. Genotype by environment iteraction, Boca Raton, FL, CRC Press, 85-122.

Hill, J., Becker, H.C., Tigerstedt, P.M.A. 1998. Quantitative and Ecological Aspects of Plant Breeding. Chapman \& Hall, London, 155-211.

Homma, S., 2015. AMMI, Stability and GGE Biplot Analysis of Durum Wheat Grain Yield for Genotypes Tested under Some Optimum and High Moisture Areas of Ethiopia. 
Academic Journal of Entomology 8(3), 132-139.

Kadhem, F.A., Baktash, F.Y., 2016. AMMI Analysis of adaptability and yield stability of promising lines of bread wheat (Triticum aestivum L.). The Iraqi Journal of Agricultural Sciences 47, 35-43.

Kang, M.S., 2002. Quantitative Genetics, Genomics and Plant Breeding. CABI Publishing Wallingford, UK, 271.

Karimizadeh, R., Mohammadi, M., Sabaghnia, N., 2013. GGE biplot analysis of yield stability in multi-environment trials of lentil genotypes under rainfed condition. Notulae Scientia Biologicae 6(2), 256-262.

Li, W., Yan, Z.H., Wei, Y.M., Lan, X.J., Zheng, Y.L., 2006. Evaluation of genotypexenvironment interactions in chinese spring wheat by the AMMI model, correlation and path analysis. Journal of Agronomy and Crop Science 192, 221-227.

Mehari, M., Tesfay, M., Yirga, H., Mesele, A., Abebe, T., Workineh, A., Amare, B. 2015. GGE biplot analysis of genotype-by-environment interaction and grain yield stability of bread wheat genotypes in South Tigray, Ethiopia. Communications in Biometry and Crop Science 10(1), 17-26.

Mohammadi, R., Mozaffar, R.M., Yousef, A., Mostafa, A., Amri, A., 2010. Relationships of phenotypic stability measures for genotypes of three cereal crops. Canadian Journal Plant Science 90, 819-830.

Mohammadi, R., Sadeghzadeh, E.D., Mohammad, A., Ahmed, A., 2011. Evaluation of durum wheat experimental lines under different climate and water regime conditions of Iran. Crop and Pasture Science 62, 137-151.

Muhammad, M., Parviz, S., Ghalamabbas, M., 2013. Additive main effect and multiplication interaction analysis of grain yield in bread wheat genotypes across environments. International Journal of Biosciences 3(8), 218-225.

Nachit, M.M., Nachit, G., Ketata, H., Gauch, Jr. H.G., Zobel, R.W., 1992. Use of AMMI and linear regression models to analyze genotype-environment interaction in durum wheat. Theoretical and Applied and Genetics 83, 597-601.

Najafian, G., Kaffasi, A.K., Jafar-Nezhad, A., 2010. Analysis of grain yield stability in Hexaploid wheat genotypes grown in temperate regions of Iran using additive main effects and multiplicative interaction. Journal Agriculture Science Technology 12, 213-222.

Annicchiarico, P., 1997. Additive main effects and multiplicative interaction (AMMI) analysis of genotype-location interaction in variety trials repeated over years. Theoretical and Applied Genetics 94, 1072-1077.

PBtools for windows. 2013. Tutorial manual. Biometrics and Bioinformatics Units. International Rice Research Institute.

Purchase, J.L., Hating, H., Van Deventer, C.S., 2000. Genotypexenvironment interaction of winter wheat (Triticum aestivum L.) in South Africa: II. Stability analysis of yield performance. S. African Journal Plant and Soil 17, 101-107.

SAS Institute, 2004. SAS/STAT user's guide.v.9.3.SAS Inst., Cary, NC.

Solomon, A., Nigussie, M., Zelleke, H., 2008. Genotypeenvironment interaction and stability analysis for grain yield of maize (Zea mays L.) in Ethiopia. Asian Journal of Plant Science 7, 163-169.

Suneetha, K., Singh, S.S., Mohapatra, T., Singh, A.M., Brajendra, Bhadana, V.P., Ravichandran, S., 2013. Genotypexenvironment interaction analysis for grain yield in new plant type (NPT wheat derivatives). SABRAO Journal of Breeding and Genetics 45(3), 382-390.

Verma, A., Chatrath, R., Sharma, I., 2015. AMMI and GGE biplots for $\mathrm{G} \times \mathrm{E}$ analysis of wheat genotypes under rain fed conditions in central zone of India. Journal of Applied and Natural Science 7(2), 656-661.

Verma, A., Tyagi, B.S., Meena, A., Gupta, R.K., Chatrath, R., 2016. Durum wheat genotypes stratification by AMMI analysis for irrigated conditions of central zone. International Journal of Tropical Agriculture 34(4), 1087-1092.

Yan,W., Hunt, L.A., Sheng, Q., Szlavnics, Z., 2000. Cultivar evaluation and mega-environment investigation based on the GGE biplot, Crop Science 40, 597-605.

Yan, W., 2002. Singular-value portioning in biplot analysis of multi environment trial data. Agronomy Journal 94, 990-996.

Yan, W., Hunt, L.A., Sheng, Q., Szlavnis, Z., 2000. Cultivar evaluation and mega-environment investigation based on the GGE biplot. Crop Science 40, 597-605.

Yan, W., Kang, M.S., 2003. GGE Biplot Analysis: A Graphical Tool for Geneticists, Breeders and Agronomists, CRC Press, Boca Raton, USA, FL., 271.

Zali, H., Farshadfar E., Sabaghpour, S.H., 2011. Non-parametric analysis of phenotypic stability in chickpea (Cicer arietinum L.) genotypes in Iran. Crop Breeding Journal 1, 89-100. 